УДК 811.161.1; 81'373

ББК 81.2:81-3

DOI: https://doi.org/10.17308/lic.2020.2/2850

\title{
СЛОВО И ДЕЛО: БЛАТ ПО ДАННЫМ ЛЕКСИКОГРАФИИ
}

\author{
С. Г. Воркачев \\ Кубанский государственный технологический университет
}

\section{WORD AND DEED: "BLAT" ACCORDING TO LEXICOGRAPHICAL DATA}

\author{
S. G. Vorkachev \\ Kuban State Technological University
}

\begin{abstract}
Аннотация: статья посвящена описанию семантических свойств, этимологии и динамики эволюции лексических показателей использования родственных и дружеских связей в обществе - лексем «блат» и «блатной». Целью статьи является выявление семантических и прагматических характеристик этих лексем на материале толковых, синонимических и этимологических словарей, а также интернет-источников лексикографического толка путем семантического анализа словарных дефиниций. Устанавливается, что использование родственных и дружеских связей, а также просто знакомств в своекорыстных интересах в человеческом обществе существовало всегда, оно хорошо вписывается в деление мира на «своих» и на «чужих». Кумовство, протекиионизм, покровительство представляют собой функииональный аналог взятки - все это инструмент индивидуального и группового выжсвания и преуспевания за счет нарушения норм справедливости. В то же самое время блат как получение каких-либо благ в обход существуюших правил при помощи личных связей - явление, в значительной мере ограниченное временнымми и пространственными рамками советского государства и своего рода индикатор эпохи. Из двух главенствующих предметных разновидностей блата (товарно-услуговой и карьерно-должностной) первая ушла в прошлое вместе с дефицитом и очередями, а для обозначения второй продолжсают существовать имена «кумовство», «протекиионизм» и «покровительство». Слово «блат» - частичный межъязыковой эквивалент: при переводе на другие языки оно находит частичное соответствие, поскольку в язык перевода транслируется лишь карьерно-должностное значение, а спеиифически советское товарно-услуговое значение остается за скобками. Несмотря на то, что слово «блат» присутствует в словниках нескольких этимологических словарей русского языка, его происхождение остается в достаточной степени неясным. В лексикографии у слова «блат» выделяются два основных значения: блат «преступление, воровство» и блат, - «связи, знакомства, дающие возможность получить что-либо, добиться чего-либо незаконным способом», между которыми никаких промежуточных семантических связей не просматривается, что дает основания считать эти значения омонимами, а не лексико-семантическими вариантами. Синонимический ряд к лексеме «блат » в значении «полезное знакомство» достаточно представителен, хотя в наиболее объемном синонимическом словаре советского времени А. П. Евгеньевой «блат» отсутствует, то ли по идеологическим соображениям, то ли по причине просторечного окраса этой лексемы. В то же самое время «блат $2_{2}$ представлен в числе многочисленных реакций на стимулы «приобретения»в ассочиативном словаре.
\end{abstract}

Ключевые слова: блат, блатной, взятка, лексикография, этимология, семантика, культурно-языковая специифика.

\begin{abstract}
: the article is devoted to the description of semantic properties, etymology and dynamics of the evolution of lexical indicators of the use of family and friendship ties in society - the tokens "blat" and "blatnoy". The purpose of the article is to identify the semantic and pragmatic characteristics of the lexical units "blat" and "blatnoy" on the material of explanatory, synonymous and etymological dictionaries, as well as Internet sources of the lexicographic character by means of a semantic analysis of vocabulary definitions of these lexemes. It is established that the use of kinship and friendship, as well as just acquaintances in selfish interests has always existed in human society, it fits well into the division of the world into "friends" and "strangers". Cronyism,
\end{abstract}

(C) Воркачев С. Г., 2020

Контент доступен под лицензией Creative Commons Attribution 4.0 License.

The content is available under Creative Commons Attribution 4.0 License. 
protectionism, patronage are a functional analogue of a bribe - all this is an instrument of individual and group survival and prosperity due to violation of justice standards. At the same time, blat as receiving any benefits bypassing existing rules through personal connections is a phenomenon largely limited by the time and space of the Soviet state and a kind of indicator of the era. Of the two dominant varieties of blat (commodity-service and career-official), the former has gone into the past along with shortages and queues, and the names "nepotism", "protectionism" and "patronage" continue to exist to denote the latter. The word "blat" is a partial interlinguistic equivalent: when translated into other languages, it finds partial correspondence, since only the career-official value is translated into the target language, and specifically the Soviet commodity-service meaning is not taken into account. Despite the fact that the word "blat" is present in several etymological dictionaries of the Russian language, its origin remains sufficiently unclear. In lexicography, the word "blat" has two main meanings: blat - "crime, theft" and blat, - "connections, acquaintances that make it possible to get something, to achieve something in an illegal way", between which no intermediate semantic connections are visible, which gives reason to consider these meanings as homonyms, and not lexical-semantic variants. The synonymic chain to the blat lexeme in the meaning of "useful acquaintance" is quite representative, although there is no "blat" in the most voluminous synonymous dictionary of the Soviet era by A. P. Evgenyeva, either for ideological reasons, or because of the vernacular color of this token. At the same time, "blat," is presented among numerous reactions to stimuli of "acquisition" in the associative dictionary.

Key words: blat, blatnoy, bribe, lexicography, etymology, semantics, culture and language specificity.

\section{Введение}

Как установлено [1, с. 5], одной из семантических составляющих идеи воздаяния выступает противопоставление сделки - обмена товарно-денежного, связанного с извлечением пользы для себя, купли-продажи - бескорыстному взаимному обмену чувствами и симпатиями, при котором «материальная часть» сугубо символична - подаркам и дарам. Обмен товарами и услугами может осуществляться на справедливых началах и признаваться обществом законным, когда обмениваются плодами собственного труда, добытыми личными усилиями. В то же самое время этот обмен может включать получение социальной ренты, связанной с преимуществами, обусловленными положением в обществе, признаваться незаконным и морально осуждаться.

«Формула блата», его структурный фрейм, в принципе, совпадает с формулой взятки: она включает такие базовые переменные, как субъект 1 - пользователь блата, непосредственный получатель выгоды, «блатной», и субъект 2 - (должностное) лицо, этот блат предоставляющее, предмет - ответная вирту-

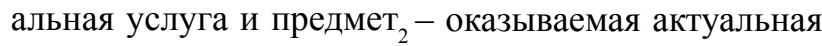
услуга. Блат и взятка - явления одного порядка, поэтому представляется вполне закономерным, что в смысловом ряду в речевом употреблении они иногда практически отождествляются. В то же самое время отличия блата от взятки коренятся, главным образом, в семантическом наполнении предмета ${ }_{1}$ - ответной услуги, которая либо виртуальна и разнесена по времени с предметом 2 - услугой актуальной, либо, при отсутствии какого-либо корыстного умысла, вовсе факультативна. С другой стороны, если предметом взятки выступают выгоды и услуги имущественного характера, предоставляемые безвозмездно, но подлежащие оплате, то предметом блата являются как раз главным образом услуги неимущественного, немате- риального характера, которые не поддаются денежному исчислению. И наконец, если взятка может принимать вид взятки-подкупа или взятки-вознаграждения (благодарности), даваться и приниматься как до, так и после оказания услуги, то ответная «блатная» услуга имеет место исключительно после оказания актуальной услуги, предоставляемой как бы в долг, и выглядит благодарностью - в противном случае это просто взятка.

\section{Материалы и методы}

«Блат» как использование личностных связей в своекорыстных интересах представляет собой достаточно специфическую разновидность взятки, выступающей своего рода гиперонимом этого имени, и, конечно, такая значимая составляющая идеи воздаяния, как мздоимство, не прошла мимо внимания российских лингвистов [2-5]. Тем не менее, насколько известно, блат как разновидность «социального бартера» - безденежного, «натурального» обмена услугами - должного лингвистического освещения еще не получил.

Исследование проведено на материале лексикографических источников: толковых, синонимических и этимологических словарей, а также текстов Интернета лексикографического характера и данных Национального корпуса русского языка. В работе использовались методы компонентного и контекстного анализа, анализ словарных дефиниций, метод межъязыкового сопоставления и метод интроспекции.

\section{Результаты исследования}

В лексической системе национального языка в результате многовековой «смысловой седиментации» постепенно откладываются история, культура и мировоззрение носителей этого языка, откладываются они, главным образом, в слове. С уходом же 
из жизни реалии, которую обозначает лексическая единица, в повседневном речевом обиходе мало-помалу сходит на нет и употребление его вербального номинанта, который превращается в историзм. С другой стороны, анализ словарных толкований какой-либо лексической единицы дает возможность установить структуру понятийных признаков соответствующей семантической категории «обыденного сознания» [6, с. 17].

Если рассматривать слово «блат» в плане межъязыковой эквивалентности как элемент межкультурной коммуникации, например, со стороны переводимости на другие языки, то здесь устанавливаются отношения «вариантного соответствия» - контекстуального и частичного, когда в языке перевода для передачи значения слова оригинала существует несколько лексических единиц [7, с. 14], и тем самым исходное слово представляется культурно специфичным, как, например, является специфичным для русского языка слово «пошлость» [8, с. 250]. Так, по данным двуязычных словарей и интернет-переводчиков слову блат в английском языке соответствуют protection, nepotism, pull, strings, string-pulling, drag, cronyism, (back-stairs) influence, clout, wangling, (profitable) connections $[9$, p. 26; 10], и все это при отсутствии инвариантного однословного эквивалента. Во французском языке ему соответствуют patronage, tutèle, favoritisme, népotisme, copinage, piston, tuyau и пр., в испанском - protección, nepotismo, favoritismo, enchufismo, amiguismo, enchufe, tirón, influjo, influencia, amparo, arrimo и пр., в турецком - iltimas, torpil, arka, kayıncılık, piston, çekme. «Расшифровка» внутренней формы этих лексических единиц позволяет распределить их по ведущему семантическому признаку в несколько тематических групп: общего покровительства (protection, protección, patronage, tutèle, favoritism, favoritismo, amparo, arrimo, iltimas), родственных и дружеских связей (nepotism, népotisme, nepotismo, kayıncılık от kayın «деверь», «шурин»; cronyism от crony «приятель», copinage от copin «приятель», amiguismo от amigo «друг»), влияния (backstairs influence, influjo, influencia). Значительная часть этих единиц образована путем метафоризации: соединения и связи (connection «связь», string «бечевка», tuуau «труба», enchufe «соединение»), проталкивания и протягивания (pull, drag «тянуть, тащить»; piston «поршень», tirón «рывок к себе», çekme «вытягивание»), удара и взрыва (clout «оплеуха», torpil «торпеда»), поддержки (arka «спина»).

Использование родственных и дружеских связей, а также просто знакомств в личных и групповых интересах в человеческом обществе существует, очевидно, от века и хорошо вписывается в деление мира на «своих», для которых все, и на «чужих», для которых закон. Кумовство, протекционизм, покрови- тельство по большому счету представляют собой функциональный аналог взятки - все это инструмент индивидуального и группового выживания и преуспевания за счет нарушения норм справедливости, как бы последние ни понимались.

В то же самое время блат как получение каких-либо благ в обход существующих правил при помощи личных связей - явление, в значительной мере ограниченное «хронотопом»: временными и пространственными рамками советского государства и отнюдь не случайно его вербальный знак включен в словник «Толкового словаря языка Совдепии» [11, c. 56]. И если рассматривать явление блата как лингвокультурный концепт, то это, безусловно, такой же «индикатор эпохи», как «сознательность» и «очковтирательство» [12, с. 161].

Наблюдения над современным речевым употреблением лексемы блат в отмеченном значении свидетельствуют о постепенном его переходе в число «забытых слов», таких как галоши, порядочность, обхождение, мещанин и пр. [13, с. 499-521], за счет утраты той части своей семантики, которая связана с порождающим его дефицитом потребительских товаров. Действительно, из двух главенствующих предметных разновидностей блата - товарно-услуговой и карьерно-должностной (достать по блату и устроиться по блату) - первая ушла в прошлое вместе с дефицитом и очередями в тот самый момент, когда восстановились рыночные, товарно-денежные отношения, а для обозначения второй продолжают существовать имена кумовство, протекционизм и покровительство.

В каком-то смысле явление, стоящее за словом блат, в межкультурной коммуникации можно считать некой «криптореалией», поскольку при переводе на другие языки оно находит частичное соответствие, когда в язык перевода транслируется лишь карьерно-должностное значение, в то время как специфически советское товарно-услуговое значение остается за скобками.

Несмотря на то, что слово блат присутствует в словниках нескольких этимологических словарей русского языка, его происхождение остается в достаточной степени неясным. Так, Макс Фасмер по фонетическому сходству возводит блат в значении «воровское арго» к польскому blat «укрыватель» из еврейско-немецкого blat «посвященный, согласный», отмечая при этом, что его происхождение от польского жаргонного blat «взятка» из немецкого *Blatt «бумажные деньги» представляется менее убедительным [14, т. 1, с. 172]. В других словарях, напротив, приводится происхождение блата уже в значении «знакомство, используемое в корыстных целях / личных интересах» как раз от польского арготического «мошенник, укрывающий по знакомству» из идиша, 
где blat «близкий (человек)» [15, с. $25 ; 16$, с. 38]. В любом случае профессиональные этимологи четких и однозначных указаний на происхождение двух основных значений современной русской лексемы

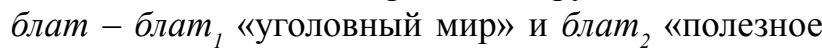
знакомство» - не дают, что, очевидно, и дает простор для спекуляций «интернет-этимологов» относительно происхождения семантического наполнения блата.

Рассуждения на эту тему варьируются от совершенно фантазийных версий до гипотез той или иной степени правдоподобия.

Так, утверждается, что блат идет из «еврейского жаргона немецкого языка», где он «означает кровь», a «достать по блату» - это «когда твои единокровные... тебе помогают добыть желаемое», что это аббревиатура от «Большие Люди Администрации Тюрьмы (БЛАТ)» - комиссия, которая решала, кого освободить досрочно [17].

Появление этого слова возводится к временам Петра I, когда оно произошло «от голландского blat или немецкого Blatt», переводимого как лист бумаги, в который «вносили имена бояр, откупившихся от позорных (с их точки зрения) процедур и повинностей: обрезания длинных рукавов, ношения немецкой одежды, бритья бород, необходимости отдавать своих недорослей для обучения ремеслу за границей и т. д.» [17], или же к временам Екатерины II, когда словом блат (от нем. Blatt - лист) обозначалась грамота, вручавшаяся немцам при переселении в Россию и дававшая такие привилегии, как освобождение от телесных наказаний, каторги, службы в армии и пр., а тех, кто имел подобные документы, называли блатнылми, а уж затем это понятие перешло в уголовный жаргон и стало означать «криминальное сообщество» [18].

Происхождение этого слова связывается с появлением иностранных технических специалистов в советское время, которым в спецмагазинах продавали товары, отсутствующие в общей продаже, по предъявлению особого документа - ордера опять же на листе бумаги [18].

И наконец, появление имени существительного блат может оказаться результатом обратного словообразования: быть производным от прилагательного блатной: в тюремной субкультуре блатныли называют касту привилегированных заключенных, пользующихся особыми привилегиями и занимающих «синекурные» по лагерным понятиям должности [19].

В лексикографии у слова блат выделяются два основных значения: блат - «преступление, воровство» [20, т. 1 , с. $151 ; 21$, т. 1, с. 106], «преступление, мошенничество» [22, т. 1, с. 501] и блат - «связи, знакомства, дающие возможность получить что-либо, добиться чего-либо незаконным способом» [23, т. 1, c. 625], «знакомство, связи, которые противозаконно можно использовать в личных интересах» [20, т. 1, c. 97]. Третье значение этого слова, выделяемое в лексикографии, - «условный язык (арго) воров» [21, т. 1 , с. $106 ; 23$, т. 1 , с. $625 ; 24$, т. 1 , с. 97$]$, «воровской язык, блатная музыка» [20, т. 1, с. 151], как представляется, производно от первого. В довоенных советских словарях Д. Н. Ушакова (1935) и С. И. Ожегова (1940) фиксируется на первом месте значение блата как преступного мира, второе значение - полезного знакомства - упоминается лишь «по касательной», в составе фразеологизма: «по блату - незаконным способом» $[20$, т. 1 , с. $151 ; 25$, с. 41]. Развернутое толкование блата как полезного знакомства появляется на втором месте в академических словарях, малом (1957-1961) и незаконченном переиздании большого (1991-1994): «знакомство, связи, которые противозаконно можно использовать в личных интеpecaх» [24, т. 1, с. 97], «связи, знакомства, дающие возможность получить что-либо, добиться чего-либо незаконным способом» [23, т. 1, с. 625]. В первом большом академическом словаре (1948-1965) дается «промежуточное» толкование: «в выражениях: получить что-либо, добыть по блату и т. п. - о незаконном способе получения чего-либо путем протекции или обмана» [22, т. 1, с. 501]. В российских толковых словарях на первом месте идет уже значение блата как полезного знакомства с пометой «разговорное», а «преступный мир» уходит на второй план с пометой «устаревшее» [21, т. 1 , с. 106; 26, с. 83].

Можно заметить, что семантический состав бла$m a$, представленный в лексикографических толкованиях, в достаточной степени скуден: здесь выделяется признак знакомства, предполагающий межсубъектный характер блата («по знакомству» [25, с. 41; «знакомство» [27, с. 50]; «связи, знакомства» [21, т. 1, c. $106 ; 24$, т. 1 , с. 97]), признак личного и корыстного интереса («личные, корыстные интересы» [27, с. 50; 26 , с. 22, с. 83], «личные, корыстные цели» [21, т. 1, c. 106]) и признак нарушения моральных и юридических норм («незаконным способом» [20, т. 1, с. 151; 23 , т. 1 , с. $625 ; 25$, с. 41$]$; «в обход существующих правил» [26, с. 83]; «путем протекции или обмана» $[22$, т. 1 , с. 501]). В силу чего блат получает отрицательную этическую оценку («неодобрительно» [27, c. 41]).

Можно также заметить, что в лексикографических толкованиях между значениями «преступный мир» и «полезное знакомство» никаких промежуточных семантических связей не просматривается, что дает бо́льшие основания считать эти значения омонимами, а не лексико-семантическими вариантами.

Синонимический ряд к лексеме блат ${ }_{2}$, составленный по данным синонимических словарей, представлен единицами завязка, замазка, знакомства, ладонь, маза, рычаги, (своя) рука, (полезные) связи, ходы (см.: $[28$, с. $169 ; 29$ с. $150 ; 30])$, куда можно еще добавить 
(волосатую/мохнатую) лапу, кумовство и книжно-литературные протекиионизм и непотизм. В наиболее объемном, двухтомном синонимическом словаре советского времени А. П. Евгеньевой [31] блат отсутствует, как, впрочем, и взятка, то ли по идеологическим соображениям, то ли по причине разговорного, просторечного и даже «вульгарного» [20, т. 1, c. 151] окраса этой лексемы.

В то же самое время блат, ассоциируемый с полезным знакомством, представлен в числе реакций на стимулы достать, заказ, выгода, деньги, знакомство, иметь, покупать, попасть, профсоюз, рука, связь «Русского ассоциативного словаря» [32, с. 37].

Наблюдения над речевым употреблением лексем блат и блатной [1, с. 330-350] подтверждают тот факт, что языковое сознание однозначно связывает стоящее за ними социальное явление с советской эпохой, блат считается специфически отечественным явлением. Существование блата в обществе жестко связывается с нехваткой товаров в открытой продаже и недоступностью услуг - тем, что в советские времена обозначалось словом дефициит. Речевое употребление этих лексем также подтверждает видовое деление блата по его предмету и области бытования, позволяющее вычленить блат товарно-услуговый и блат карьерно-должностной. В отличие от блата товарно-услугового, который ушел вместе с советской властью, блат карьерно-должностной, напротив, в постсоветской России расцвел пышным цветом. Места, на которые устраивают и на которые пристраиваются по блату, - это должности престижные и денежные, только денежные или только престижные, а также синекурные, не требующие больших трудовых усилий. Оценочное отношение языкового сознания к блату двойственно. Со стороны общественной морали блат осуждается однозначно и бескомпромиссно, он отождествляется с нечестностью, непорядочностью, с отсутствием интеллигентности. В то же самое время праксеологически, со стороны возможностей получать личную, индивидуальную пользу блат оценивается вполне положительно.

\section{Выводы}

Использование родственных и дружеских связей, а также просто знакомств в личных и групповых интересах в человеческом обществе существует, очевидно, от века и хорошо вписывается в деление мира на «своих» и на «чужих». Кумовство, протекционизм, покровительство по большому счету представляют собой функциональный аналог взятки - все это инструмент индивидуального и группового выживания и преуспевания за счет нарушения норм справедливости. В то же самое время блат как получение каких-либо благ в обход существующих правил при помощи личных связей - явление, в значительной мере ограниченное временными и пространственными рамками советского государства и своего рода индикатор эпохи.

Из двух главенствующих предметных разновидностей блата (товарно-услуговой и карьерно-должностной) первая ушла в прошлое вместе с дефицитом и очередями, а для обозначения второй продолжают существовать имена «кумовство», «протекционизм» и «покровительство».

Слово блат - частичный межъязыковой эквивалент: при переводе на другие языки оно находит частичное соответствие, поскольку в язык перевода транслируется лишь карьерно-должностное значение, а специфически советское товарно-услуговое значение остается за скобками.

Несмотря на то, что слово блат присутствует в словниках нескольких этимологических словарей русского языка, его происхождение остается в достаточной степени неясным. В лексикографии у слова блат выделяются два основных значения: блат «преступление, воровство» и блат - - «связи, знакомства, дающие возможность получить что-либо, добиться чего-либо незаконным способом», между которыми никаких промежуточных семантических связей не просматривается, что дает основания считать эти значения омонимами, а не лексико-семантическими вариантами.

Синонимический ряд к лексеме блат, в значении «полезное знакомство» достаточно представителен, хотя в наиболее объемном синонимическом словаре советского времени А. П. Евгеньевой блат отсутствует, то ли по идеологическим соображениям, то ли по причине просторечного окраса этой лексемы. В то же самое время блат, представлен в числе многочисленных реакций на стимулы «приобретения» в ассоциативном словаре.

\section{ЛИТЕРАТУРА}

1. Воркачев С. Г. Какою мерою мерите : идея воздаяния в лингвокультуре. М. : Флинта, 2020. 372 с.

2. Баранов А. Н. Метафорические грани феномена коррупции // Общественные науки и современность. PAH. 2004. № 2. С. 70-79.

3. Марченко О. В. Семантический анализ слова взятка, или Сколько лексических лакун может скрывать одно юридическое понятие // Вестник Моск. ун-та. Cер. 19. Лингвистика и межкультурная коммуникация. 2014. № 1. С. 26-32.

4. Плотникова А. М., Старикова К. В. Динамика лексико-семантического поля «взятка» в русском языке // Вестник Самар. ун-та. История, педагогика, филология. 2016. № 3-2. С. 51-56.

5. Шипищина Г. М. Историко-лингвистический взгляд на концепт взяточничество // Уральский филологический вестник. Серия: Язык. Система. Личность. Лингвистика креатива. 2016. № 2. С. 296-305. 
6. Воркачев С. Г. Imago verbi : опыт семантического портретирования имени. М. : Флинта-Наука, 2017. 284 с.

7. Реикер Я. И. Теория перевода и переводческая практика. М. : Международные отношения, 1974. 216 с.

8. Воркачев С. Г. «Госпожа Пошлость» : наброски к семантическому портрету // Вестник Пятигор. гос. ун-та. 2017. № 4. С. 250-254.

9. The Oxford Russian Dictionary. Oxford-NY : Oxford UP, 1997. 1340 p.

10. Wooordhunt. URL: http://wooordhunt.ru/word/блат

11. Мокиенко В. М., Никитина Т. Г. Толковый словарь языка Совдепии. СПб. : Фолио-пресс, 1998. 700 с.

12. Карасик В. И. Языковая кристаллизация смысла. М. : Гнозис, 2010. $351 \mathrm{c.}$

13. Пьеиух В. Забытые слова (синодик) // Низкий жанр. М. : ЗебраЕ, 2005. С. 499-521.

14. Фасмер М. Этимологический словарь русского языка : в 4 т. М. : Астрель-АСТ, 2003.

15. Шанский Н. М., Боброва Т. А. Школьный этимологический словарь русского языка : происхождение слов. М. : Дрофа, 2000. 400 с.

16. Крылов Г. А. Этимологический словарь русского языка. СПб. : Полиграфуслуги, 2005. 432 с.

17. Что значит выражение «достать по блату». URL: http://otvet.mail.ru/question/24786318

18. Википедия. URL: https://ru.wikipedia.org/w/index. php?title=Блат\&oldid $=87934334$

19. Лукоморье. URL: http://lurkmore.to/Блат

20. Ушаков Д. Н. Толковый словарь русского языка : в 4 т. М. : Астрель-АСТ, 2000.

21. Ефремова T. Ф. Новый словарь русского языка. Толково-словообразовательный : в 2 т. М. : Русский язык, 2001.

22. Словарь современного русского литературного языка : в 17 т. М. ; Л. : АН СССР, 1951-1965.

23. Словарь современного русского литературного языка : в 20 т. М. : Русский язык, 1991-1994.

24. Словарь русского языка : в 4 т. М. : Русский язык, 1981-1984.

25. Ожегов С. И. Словарь русского языка. М. : Госиздат иностранных и национальных словарей, 1953. $848 \mathrm{c}$.

26. Кузнецов C. А. Большой толковый словарь русского языка. СПб. : Норинт, 1998. 1536 с.

27. Ожегов С. И., Шведова Н. Ю. Толковый словарь русского языка. М. : Азбуковник, 1998. 944 с.

28. Александрова 3. Е. Словарь синонимов русского языка : ок. 9000 синонимических рядов. М. : Русский язык, $1986.600 \mathrm{c.}$

29. Александрова 3. Е. Словарь синонимов русского языка. Практический справочник : ок. 11000 синонимических рядов. М. : Русский язык, 2001. 568 с.

30. Тришин В. Н. Словарь синонимов ASIS, 2010. URL: http://sinonim-slovo.info/Словарь_синонимов

31. Евгеньева А. П. Словарь синонимов русского языка : в 2 т. М. : Астрель-Аст, 2001.

32. Русский ассоциативный словарь : в 2 т. Т. 2 : От реакции к стимулу. М. : АСТРЕЛЬ-АСТ, 2002. 992 с.

\section{REFERENCES}

1. Vorkachev S. G. Kakoyu meroyu merite: ideya vozdayaniya $v$ lingvokul'ture [With the Measure You Use: the Idea of Retribution in Linguistic Culture]. Moscow: Flinta, 2020. 372 p.

2. Baranov A. N. Metaforicheskiye grani fenomena korruptsii [Metaphorical facets of the phenomenon of corruption]. In Obshchestvennyye nauki i sovremennost' [Social Sciences and Modernity]. RAN. 2004. No. 2. Pp. 70-79.

3. Marchenko O. V. Semanticheskiy analiz slova vzyatka ili Skol'ko leksicheskikh lakun mozhet skryvat' odno yuridicheskoye ponyatiye [The semantic analysis of the word bribe or How many lexical lacunae can hide one legal concept]. In Vestnik Moskovskogo universiteta, ser. 19: Lingvistika i mezhkul'turnaya kommunikatsiya [Moscow University Bulletin, Ser. 19: Linguistics and intercultural communication]. 2014. No. 1. Pp. 26-32.

4. Plotnikova A. M., Starikova K. V. Dinamika leksiko-semanticheskogo polya «vzyatka»v russkom yazyke [The dynamics of the lexical-semantic field "bribe" in the Russian]. In Vestnik Samarskogo universiteta. Istoriya, pedagogika, filologiya [Bulletin of Samara University. History, Pedagogy, Philology]. 2016. No. 3-2. Pp. 51-56.

5. Shipitsina G. M. Istoriko-lingvisticheskiy vzglyad na kontsept vzyatochnichestvo [The historical-linguistic view of the concept of bribery]. In Ural'skiy filologicheskiy vestnik. Seriya: Yazyk. Sistema. Lichnost'. Lingvistika kreativa [Ural Philological Bulletin. Series: Language. System. Personality. Creative Linguistics]. 2016. No. 2. Pp. 296-305.

6. Vorkachev S. G. Imago verbi: opyt semanticheskogo portretirovaniya imeni [Imago Verbi: Essay of Semantic Portrait of the Name]. Moscow: Flinta-Nauka, 2017. 284 p.

7. Retsker Ya. I. Teoriya perevoda i perevodcheskaya praktika [Theory of Translation and Translation Practice]. Moscow: Mezhdunarodnyye otnosheniya, 1974. 216 p.

8. Vorkachev S. G. «Gospozha Poshlost'»: nabroski $k$ semanticheskomu portretu [Madam vulgarity": outline for a semantic portrait]. In Vestnik Pyatigorskogo gosudarstvennogo universiteta [Bulletin of the Pyatigorsk State University]. 2017. No. 4. Pp. 250-254.

9. The Oxford Russian Dictionary. Oxford-NY: Oxford UP, $1997.1340 \mathrm{p}$.

10 Wooordhunt. Available at: http://wooordhunt.ru/ word/blat

11. Mokiyenko V. M., Nikitina T. G. Tolkovyy slovar' yazyka Sovdepii [Explanatory Dictionary of the Language of the Soviets]. St. Petersburg: Folio-press, 1998. 700 p.

12. Karasik V. I. Yazykovaya kristallizatsiya smysla [Language Crystallization of Meaning]. Moscow: Gnozis, 2010.351 p.

13. P'yetsukh V. Zabytyye slova (sinodik) [Forgotten words (synodic)]. In Nizkiy zhanr [Low Genre]. Moscow: ZebraE, 2005. Pp. 499-521.

14. Fasmer M. Etimologicheskiy slovar' russkogo yazyka: $v 4 t$. [Etymological Dictionary of the Russian Language: in 4 vols]. Moscow: Astrel'-AST, 2003. 
15. Shanskiy N. M., Bobrova T. A. Shkol'nyy etimologicheskiy slovar' russkogo yazyka: Proiskhozhdeniye slov [School Etymological Dictionary of the Russian Language: The Origin of Words]. Moscow: Drofa, 2000. 400 p.

16. Krylov G. A. Etimologicheskiy slovar' russkogo yazyka [Etymological Dictionary of the Russian Language]. St. Petersburg: Poligrafuslugi, 2005. 432 p.

17. Chto znachit vyrazheniye "dostat' po blatu» [What does the expression "get by pull" mean]. Available at: http:// otvet.mail.ru/question/24786318

18. Vikipediya [Wikipedia]. Available at: https://ru. wikipedia.org/w/index.php?title=Blat\&oldid=87934334

19. Lukomor'ye [Lurkmore]. Available at: http://lurkmore.to/Blat

20. Ushakov D. N. Tolkovyy slovar' russkogo yazyka: $v 4 t$. [Explanatory Dictionary of the Russian Language: in 4 vols]. Moscow: Astrel'-AST, 2000.

21. Yefremova T. F. Novyy slovar' russkogo yazyka. Tolkovo-slovoobrazovatel'nyy: $v 2 t$. [New Dictionary of the Russian Language. Interpretative and Derivational: in 2 vols]. Moscow: Russkiy yazyk, 2001.

22. Slovar' sovremennogo russkogo literaturnogo ya$z y k a: v 17 t$. [Dictionary of the Modern Russian Literary Language: in 17 vols]. Moscow-Leningrad.: USSR Academy of sciences, 1951-1965.

23. Slovar' sovremennogo russkogo literaturnogo ya$z y k a: v 20 t$. [Dictionary of Modern Russian Literary Language: in 20 vols]. Moscow: Russkiy yazyk, 1991-1994.

24. Slovar' russkogo yazyka: v 4 t. [Dictionary of the Russian Language: in 4 vols]. Moscow: Russkiy yazyk, 1981-1984.

Кубанский государственный технологический университет

Воркачев С. Г., доктор филологических наук, профессор кафедры иностранных языков

E-mail: svork@mail.ru

Поступила в редакциюю 12 декабря 2019 г.

Принята к публикачии 25 марта 2020 г.

\section{Для иитирования:}

Воркачев С. Г. Слово и дело: БЛАТ по данным лексикографии // Вестник Воронежского государственного университета. Серия: Лингвистика и межкультурная коммуникация. 2020. № 2. C. 145-151. DOI: https://doi. org/10.17308/lic.2020.2/2850
25. Ozhegov S. I. Slovar' russkogo yazyka [Dictionary of the Russian Language]. Moscow: Gosizdat inostrannykh i natsional'nykh slovarey, $1953.848 \mathrm{p}$.

26. Kuznetsov S. A. Bol'shoy tolkovyy slovar' russkogo yazyka [Large Explanatory Dictionary of the Russian Language]. St. Petersburg: Norint, 1998. 1536 p.

27. Ozhegov S. I., Shvedova N. Yu. Tolkovyy slovar' russkogo yazyka [Explanatory Dictionary of the Russian Language]. Moscow: Azbukovnik, 1998. 944 p.

28. Aleksandrova Z. Ye. Slovar' sinonimov russkogo yazyka: ok. 9000 sinonimicheskikh ryadov [Dictionary of Synonyms of the Russian Language: approx. 9000 synonymous series]. Moscow: Russkiy yazyk, 1986. $600 \mathrm{p}$.

29. Aleksandrova Z. Ye. Slovar' sinonimov russkogo yazyka. Prakticheskiy spravochnik: ok. 11000 sinonimicheskikh ryadov [Dictionary of Synonyms of the Russian Language. Practical Guide: approx. 11000 synonymous series]. Moscow: Russkiy yazyk, 2001. 568 p.

30. Trishin V. N. Slovar' sinonimov ASIS, 2010 [Dictionary of Synonyms ASIS, 2010]. Available at:: http://sinonim-slovo.info/Slovar' sinonimov

31. Yevgen'yeva A. P. Slovar' sinonimov russkogo ya$z y k a$ : $v 2 t$. [Dictionary of Synonyms of the Russian Language: in 2 volumes]. Moscow: Astrel'-Ast, 2001.

32. Russkiy assotsiativnyy slovar': v 2 t. T. 2: Ot reaktsii $k$ stimulu. [Russian Associative Dictionary: in 2 vols. T. 2: From Reaction to Stimulus]. Moscow: ASTREL'-AST, 2002. 992 p.

Kuban State Technological University

Vorkachev S. G., Doctor of Philology, Professor of the Foreign Languages Department

E-mail:svork@mail.ru

Received: 12 December2019

Accepted: 25 March 2020

\section{For citation:}

Vorkachev S. G. Word and Deed: "Blat" According to Lexicographical Data. Proceedings of Voronezh State University. Series: Linguistics and Intercultural Communication. 2020. No. 2. Pp. 145-151. DOI: https://doi. org/10.17308/lic.2020.2/2850 